\title{
Prática de Informática na Educação: Ambiente de Experiência ITAE com alunos da Universidade de Brasília (UnB)
}

\author{
JORge Luís bARRETo PEREIRA ${ }^{1}$, ANA CLARA BONINI-ROCHA ${ }^{2}$ \\ ${ }^{1}$ UnB - Universidade Brasília CDT - Centro de Apoio ao Desenvolvimento Tecnológico \\ Caixa Postal: 04397. CEP 70.904-970. Brasília - Distrito Federal (DF). \\ ${ }^{2}$ UnB - Universidade Brasília - FCE - Faculdade de Ceilândia - Centro Metropolitano \\ Conjunto A - Lote 1. CEP 72.220.900. Brasília - Distrito Federal (DF). \\ jorge.pereiradcdt.unb.br, anaclara@unb.br
}

\begin{abstract}
This article presents the Educational Experience Environment developed in the Innovation Technological Laboratory for Experience Environment (ITAE) of the Technological Development Support Center (CDT) at University of Brasilia $(U n B)$. It aims to show the evaluation of 306 students who have played the games developed for the environment, showing the results obtained from the opinion survey about motivation, satisfaction and perception of learning after the experience. Those results have showed that the ITAE environment has been efficient in its goals. The student opinions have showed a delightful experience, with a consistent and well distributed content, that was capable to motivate and stimulate learning.
\end{abstract}

Resumo: Este artigo apresenta o Ambiente de Experiência Educacional, desenvolvido no Laboratório de Inovações Tecnológicas para Ambientes de Experiência (ITAE) do Centro de Apoio ao Desenvolvimento Tecnológico (CDT) da Universidade de Brasília (UnB). Tem como objetivo mostrar a avaliação dos 306 discentes que participaram dos jogos vinculados ao ambiente, divulgando os dados obtidos no preenchimento de questionário de opiniões sobre motivação, satisfação e percepção de aprendizagem após a experiência. Observou-se pelos resultados que o ambiente ITAE foi eficiente naquilo que se dispôs a fazer. As opiniões dos alunos mostraram que foi uma experiência agradável, de conteúdo coerente e bem distribuído, que foi capaz de motivar e incentivar aprendizagem.

\section{Introdução}

A década de 90 do século XX consolidou a presença de computadores nos ambientes de praticamente todas as áreas de trabalho e de conhecimento - a qual vinha sendo silenciosa pelo uso familiar e de pesquisa científica.

O impacto causado pela tecnologia computacional na área da educação é evidente. As novas formas de apresentação de conteúdos pela internet estão interferindo diretamente no comportamento dos professores, sua demanda metodológica e reprodutibilidade de conteúdos, conforme já havia apontado Maria Isabel Timm e seus colaboradores, em 2007, no artigo intitulado 'A virada computacional da filosofia'. 
Historicamente, o centro do processo ensino-aprendizagem tradicional tem se centrado na atuação do professor e se baseado na concepção de transferência de conhecimento. Atualmente, abordagens educacionais baseadas em novas metodologias são focadas na aprendizagem do estudante e nas relações que este estabelece com as pessoas e experiências que o cercam (Mota, 2010).

Isso porque, hoje, os educadores têm como público-alvo uma geração de alunos com acesso a rápidos e dinâmicos meios de comunicação (Timm et al., 2007; Zaro et al., 2010).

O uso da Internet está disseminado pelos espaços educacionais, dentro e fora da sala de aula, integrando-se, cada vez mais, na realidade do ambiente escolar. Assim, tecnologia e inovação, como apoio à estruturação de novas propostas para enriquecer o processo educacional, é a palavra de ordem.

Nesse sentido, pesquisadores brasileiros têm proposto reflexões sobre as mais amplas temáticas relacionando informática com metodologias educacionais. Alguns dos principais estudos tratam de possibilidades tecnológicas e ambientes virtuais relacionados à cognição (Azevedo et al., 2004; Cabral et al., 2005; Timm et al., 2003; 2004; 2008; 2009ab; Azevedo 2008; Paula, 2010; Pelosi, 2010; Bruno, 2010). O fato é que, novas tecnologias educacionais, sua inexorabilidade e seu enorme potencial para impor a atualização sobre as novas necessidades e formas de ensinar e de aprender, produzem sentido e complexidade compatível com o conhecimento necessário ao educando e educador do Século XXI (Zaro et al. 2010).

Por isso, os educadores do século XXI estão se perguntado sobre estratégias adequadas para interagir com essa geração de alunos que tem acesso a modernos meios de comunicação liderados pela Internet.

Tomando-se como exemplo as tecnologias de vídeo como recurso de ensino, a vídeoaula é capaz de integrar múltiplas mídias e linguagens, com superposição de códigos e significações predominantemente audiovisuais, apoiadas no discurso narrado e escrito. Tem a vantagem de documentar um conhecimento, enquanto comunica de forma similar e/ou complementar ao que é disponibilizado em sala de aula, tendo em vista atingir determinados objetivos de ensino (Almeida, 2003; Pereira et al., 2007). Cabe, no entanto, ao professor a tarefa de organizar um planejamento criterioso que indique as ocasiões adequadas para seu uso, em momentos de exposição de conteúdos. É essencial que o professor seja, de fato, um instrumento mediador da aprendizagem com uma sequência de apresentação de conteúdo condizente com as necessidades didático-pedagógicas de seus alunos (Wojciechowski, Vosgerau, 2010).

Considerando-se, então, a importância das aulas expositivas e um mundo de novas possibilidades à disposição dos alunos para acessarem os conhecimentos, é ponto crítico a maneira como o professor faz a mediação entre os recursos que tem e os conteúdos que deve desenvolver em sala de aula e fora dela. A ação do professor deve estar diretamente relacionada à aprendizagem do aluno (Almeida, 1993; Soares, 2010). Em décadas atrás, Bushell (1973) já havia atribuído o fracasso da aprendizagem ao fracasso do ensino. Para ele, não havia coerência em se afirmar que se ensinou bem, mas que o aluno não aprendeu. $\mathrm{O}$ sucesso de ensinar estaria em obter a motivação, a satisfação e a aprendizagem do aluno e não pela intenção ou objetivo do professor de ensinar. A relação entre o que o professor faz e a 
efetiva aprendizagem do aluno seria o que, mais apropriadamente, poderia ser chamado de ensinar.

Expectativas positivas de resultados, pelos alunos, pode aumentar a motivação e é em função delas que levarão à escolha, à direção e à persistência nos comportamentos de aprendizagem (Bzuneck, 2007). Quando um aluno tem boa percepção de aprendizagem, sua crença, ou autopercepção de capacidades, chamada de metacognição, diz respeito a suas convicções pessoais quanto à própria inteligência, habilidades e conhecimentos, o que pode gerar muita satisfação e motivação.

Satisfação, motivação e percepção de aprendizagem são aspectos interrelacionados, que se autoinfluenciam. Por isso, esses fatores são critérios importantes para a escolha das metodologias de ensino, cujos objetivos didático-pedagógicos são estimular a imaginação, intuição, colaboração e impacto emocional que, por certo, surtirão efeito satisfatório no envolvimento dos alunos com a aprendizagem (Moraes, Torre, 2004).

Indo na corrente desta tendência, a Universidade de Brasília (UnB), no Laboratório de Inovações Tecnológicas para Ambientes de Experiência do Centro de Apoio ao Desenvolvimento Tecnológico (ITAE/CDT), está propondo uma experiência de utilização da tecnologia computacional na educação com alunos da disciplina de Introdução à Atividade Empresarial (IAE) e de disciplinas da Ciência da Informação (CI). Os alunos disputam jogos num ambiente virtual denominado de ITAE que os ajuda a fixar os conteúdos de disciplinas curriculares de maneira divertida e que estimula o trabalho em equipe.

O Jogo tem como objetivo trabalhar vários sentidos do estudante para que ele se sinta imerso na experiência, não se disperse e seja motivado a participar ativamente, revendo e aprendendo conceitos de forma lúdica. É uma ferramenta de apoio pedagógico para complementar a aula expositiva ou dada de outra maneira.

Como Ambiente de Experiência, o ITAE se baseia em quatro pilares: educação, imersão, entretenimento e estética. Conforme os princípios da Economia da Experiência o aprendizado é mais efetivo se envolvermos ao máximo os sentidos, em um ambiente agradável e divertido.

O jogo ITAE foi desenvolvido com o objetivo de imergir os jovens totalmente na experiência de aprendizagem, motivando alunos desmotivados, envolvendo-os ao ponto de fazê-los participarem das atividades acadêmicas esquecendo o resto do mundo por algumas horas. Este ambiente não é fechado, permitindo a inclusão de vídeos, textos, sons, músicas, etc. E pode ser usado em várias disciplinas e atividades da UnB, podendo ser adaptado conforme as necessidades apresentadas, dependendo da criatividade de quem quiser ensinar e aprender. O ITAE pode ser contratado para agregar valor a qualquer curso, trabalhando a motivação, o comportamento e reforçando a assimilação do conteúdo programático.

Ao lado de cinco estagiários da engenharia, computação e design, o Engenheiro Jorge Pereira trabalha desde maio de 2011 nos jogos usados atualmente no laboratório: Quiz e Batalha. Divididos em dois grupos, em uma sala equipada, grandes mesas com telas ativadas pelo toque promovem disputas que envolvem questões de verdadeiro ou falso, múltipla escolha e disputas contra adversários em partidas de batalha naval. O número de disparos a que cada grupo tem direito é definido pela taxa de acerto. Todas as ações são controladas pela mesa interativa. 
Esse artigo inicia com uma apresentação geral do ambiente ITAE e suas características. Entretanto, o objetivo do manuscrito é apresentar dados que demonstrem que o ambiente foi útil ao objetivo que se dispôs a alcançar: basicamente de ser uma vivência agradável, motivacional, que facilite processo de aprendizagem de conteúdos de ciências e tecnologias, otimizando o tempo de divertimento com tempo de aprendizagem. Até agora, 306 alunos, de 2012 a 2013, participaram da experiência e responderam aos questionários de opinião sobre satisfação de tal metodologia como prática de ensino.

\section{O jogo ITAE}

O ITAE é um moderno ambiente usado para capacitação por meio de jogos de imersão. Possui controle automatizado de som, luz e projeções por reconhecimento de voz e por dispositivos de toque. Foi desenvolvido pelo laboratório de Inovações Tecnológicas para Ambientes de Experiência do Centro de Apoio ao Desenvolvimento Tecnológico (CDT) da UnB.

O Jogo ITAE é do tipo quiz, mas com um jogo entre as perguntas. Respondendo-se às perguntas, podem-se ganhar recursos para entrar no jogo. Quanto mais recursos se obtêm, mais jogadas podem ser feitas. Pode-se escolher qual jogo haverá entre as perguntas. No momento há duas opções: Quebra-cabeça, onde uma figura relacionada ao assunto será montada e o número de peças da figura vai aumentando conforme os quebra-cabeças mais fáceis são completados; e Batalha Naval, onde o objetivo é afundar a esquadra distribuída pelo oponente no campo de batalha.

No Laboratório há toda uma interação com o ambiente automatizado de luzes e sons. $\mathrm{Na}$ Batalha Naval há dois piratas que comandam as tripulações que competem: o Capitão Muralha e o Pirata Barba Rala. O Jogo ITAE pode ser moldado conforme o que se deseja, trocando-se o conteúdo facilmente. Também permite a inserção de vídeos, figuras, textos e outros arquivos entre as perguntas. Pode-se, por exemplo, colocar vídeo aulas antes da pergunta ou em caso de erro ou acerto da mesma, mantendo-se ou retirando-se os jogos. Com isto pode-se montar uma estória que eventualmente remeta ao público uma pergunta. Basta produzir ou escolher os vídeos e elaborar as questões. A configuração do software para chamar cada trecho na hora apropriada é feita de forma fácil e rápida.

\subsection{Detalhando o ITAE}

É um laboratório de $80 \mathrm{~m} 2$ com duas mesas de 230x170cm (aproximadamente 112 polegadas) sensíveis ao toque para permitir jogos em equipe. Também dispõe de duas telas SmartBoard, 5 televisores, 4 projetores, uma rede de 12 computadores , um mixer (controle de áudio) e um dimmer (controle de iluminação).

Foram desenvolvidos softwares que permitem controlar 12 canais de luzes, o áudio ambiente e definir o que será projetado nas mesas, nos televisores e nas telas através de uma interface de toque. Isso também pode ser feito por comandos de voz.

A interface por comandos de voz permite chamar o laboratório para que ele cumprimente o público e atenda aos pedidos. Esses pedidos podem ser para ligar ou desligar as luzes de cada canal separadamente, configurar as diversas opções do jogo e iniciar o mesmo.

A estrutura montada permite criar comandos de voz específicos para reproduzir vídeos e sons no dispositivo da rede que se deseja, com pequenas mudanças no software. 


\subsection{O Hardware}

O jogo ITAE pode ser jogado em qualquer ambiente além do laboratório. Pode ser jogado em computadores com mouse ou com monitores sensíveis a toque e também em telas, quadros e mesas sensíveis a toque.

ITAE foi concebido para ser jogado em equipe, mas pode ser jogado solitariamente. Pode também haver uma única equipe jogando colaborativamente, sem competição. Mas o usual é uma competição entre dois ou mais jogadores ou entre duas ou mais equipes. $\mathrm{O}$ número de jogadores em cada equipe pode variar de 1 a 10 . Na configuração atual são permitidas até nove equipes, mas isso pode ser ampliado se for preciso.

O número de jogadores de cada equipe vai depender da interface escolhida. Se houver uma mesa ou tela grande, cada jogador tem seu próprio botão para concordar ou não com a escolha da equipe. Mas se a interface não permitir, pode-se escolher um membro da equipe para acionar a interface e os demais participam dando opiniões. A princípio o jogo não precisa de uma interface específica para funcionar desde que o sistema operacional seja Linux, Windows ou Mac Os.

\subsection{A Batalha}

Batalha ITAE é um jogo que mistura Quiz com Batalha Naval. Foi concebido para ser jogado coletivamente entre equipes. Na primeira parte do Jogo as equipes decidem onde posicionam suas esquadras no campo de batalha. São dois navios de três peças, quatro navios de duas peças, e seis navios de uma peça; somando 12 navios, 20 peças. Cada peça ocupa uma posição no campo de batalha, que possui 81 posições numa matriz de nove linhas por nove colunas. bônus.

Se a equipe distribui a esquadra dentro do prazo estabelecido ela ganha uma jogada de

Quando todas as equipes terminarem de posicionar suas esquadras, as perguntas começam a ser enviadas para as equipes e o tempo do jogo começa a ser contado. Esse tempo é configurado antes do jogo.

Cada pergunta tem um tempo para ser respondida. Esse tempo é configurado antes do jogo começar. Se não houver resposta neste tempo, a equipe recebe zero ponto pela pergunta e o jogo envia a próxima. Os jogadores devem acionar a resposta certa e cada um precisa apertar seu botão de confirmação para manifestar sua concordância com a resposta dada. Em seguida é apresentado o gabarito com a marcação de certo ou errado para cada item da pergunta. Nesta hora os jogadores devem estar atentos, pois, se algum item está errado a pergunta vai para a fila de repetidas. No final do jogo, a fila de repetidas começa a ser enviada para a equipe ter nova oportunidade de acertar a pergunta. Se a resposta não estiver completamente certa, ela volta para a fila de repetidas novamente.

Junto com o gabarito há uma animação com a voz de um dos piratas dando uma mensagem de incentivo, reclamação ou "zoando" com o adversário.

Após a apresentação do gabarito cada jogador deve acionar seu botão para dizer que já assimilou o gabarito e o jogo deve continuar. Então é apresentada na tela os recursos obtidos com a resposta. No início do jogo cada três recursos obtidos dão direito a uma jogada. É o momento de entrar na batalha. 
A batalha permite dois tipos de jogada: dica ou tiro. As dicas se encontram nas laterais do campo de batalha e informam quantos navios existem na linha ou coluna em que elas se encontram. Há um som e uma animação de um baú de tesouro. Essa é uma jogada estratégica para que a localização da esquadra inimiga não seja somente sorte. O tiro é dado ao se apertar uma das 81 posições da matriz e em seguida apertar o botão de confirmação. A cada jogada somente um jogador terá seu botão de confirmação aceso, para indicar que ele é quem deve decidir o que será feito nesse momento. Todos terão sua vez, alternadamente, a cada jogada.

Após ter efetuado todas as jogadas permitidas a equipe recebe a pergunta seguinte para tentar obter novas jogadas. Sempre que não houver acúmulo de recursos suficientes para entrar na batalha, o jogo envia imediatamente a pergunta seguinte.

O jogo pode acabar pelo tempo ou quando uma equipe responde a todas as perguntas. Mas é preciso responder todas as repetidas sem errar nenhuma.

Vence o jogo quem conseguir mais pontos que são obtidos ao afundar navios do adversário. O valor de cada peça afundada depende do tamanho do barco. As peças dos barcos menores valem mais, mas os barcos maiores afundados completamente marcam mais pontos.

Quando o jogo é no laboratório há ainda o som dos tiros e das explosões, na água ou nos navios, reproduzida no ambiente, assim como luzes vermelhas piscando quando uma peça é atingida simulando o incêndio da explosão. Também há frases de comemoração dos piratas sempre que conseguem ultrapassar a pontuação do oponente.

As perguntas precisam ser bem elaboradas para o jogo ficar interessante. Elas devem gerar reflexão e diálogo da equipe. São três tipos de pergunta: Múltipla Escolha, Verdadeiro/Falso, e Associativa. Cada uma pode ter no máximo cinco alternativas ou itens. Há um programa próprio para gerar as perguntas para o jogo. É como preencher um formulário digitalmente. Portanto qualquer assunto pode ser inserido no jogo, basta que haja um especialista para elaborar as questões.

\section{Resultados}

Os dados dizem respeito à pesquisa de opinião com os alunos da UnB envolvidos no projeto de experiência no ambiente ITAE quanto à motivação, satisfação e percepção de aprendizagem. Dentre as disciplinas envolvidas apresentamos a pesquisa feita em IAE no segundo semestre do ano de 2012. Os resultados somam alunos de 10 turmas, apresentando 306 respostas conforme as figuras 1 a 4 apresentadas logo abaixo. 


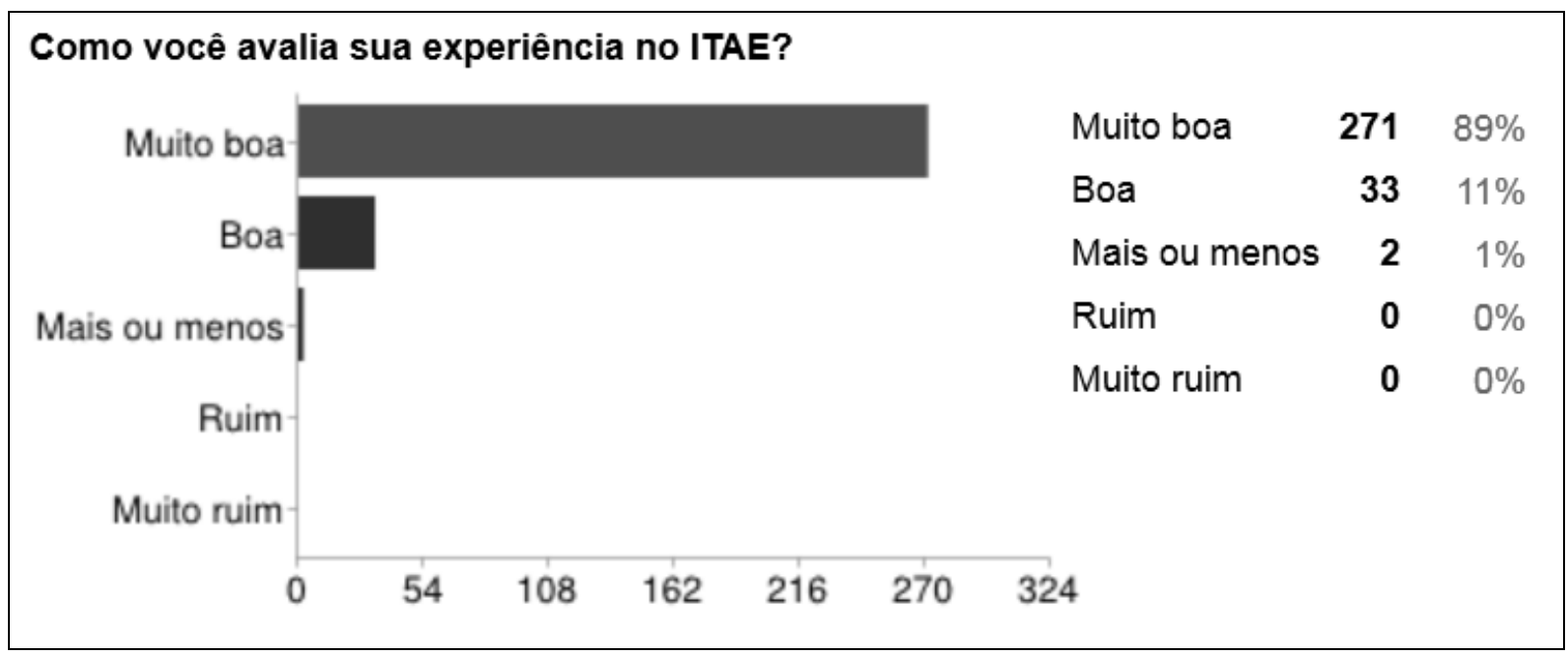

Figura 1: Respostas do questionário de opiniões após a experiência com o ITAE referente à satisfação frente ao jogo. Total de 306 alunos do curso de IAE.

\section{Como você avalia o tempo da experiência?}

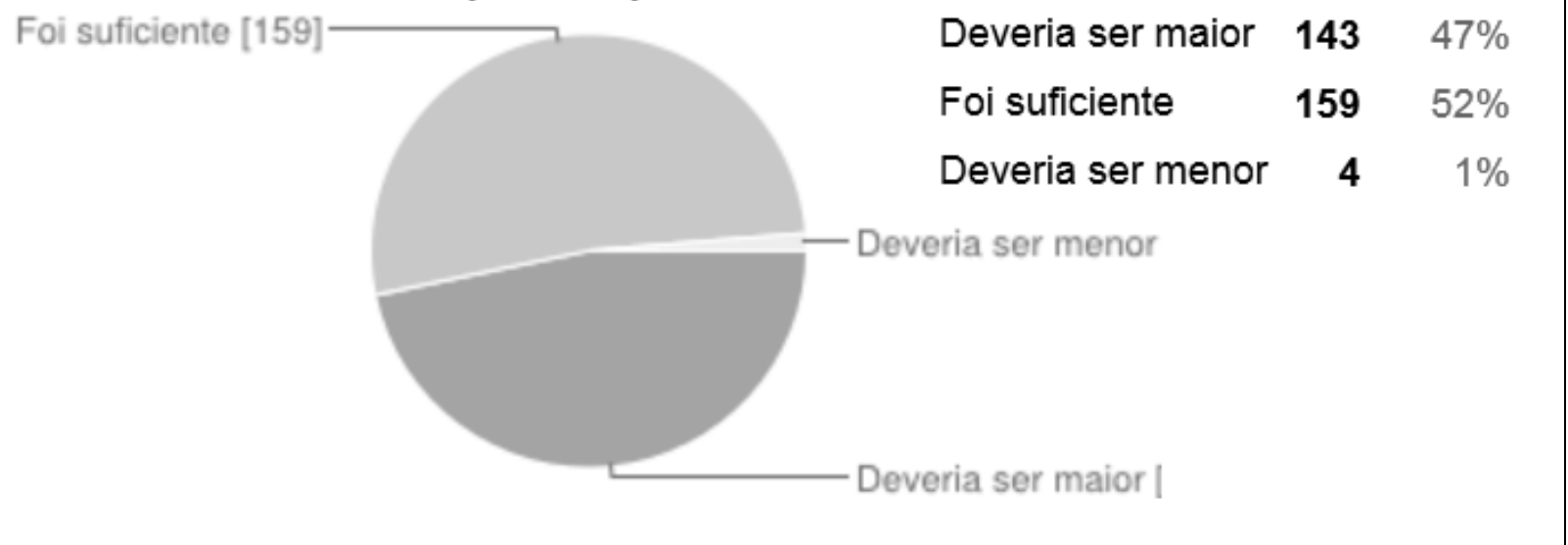

Figura 2: Respostas do questionário de opiniões após a experiência com o ITAE referente à satisfação frente ao tempo de jogo. Total de 306 alunos do curso de IAE.

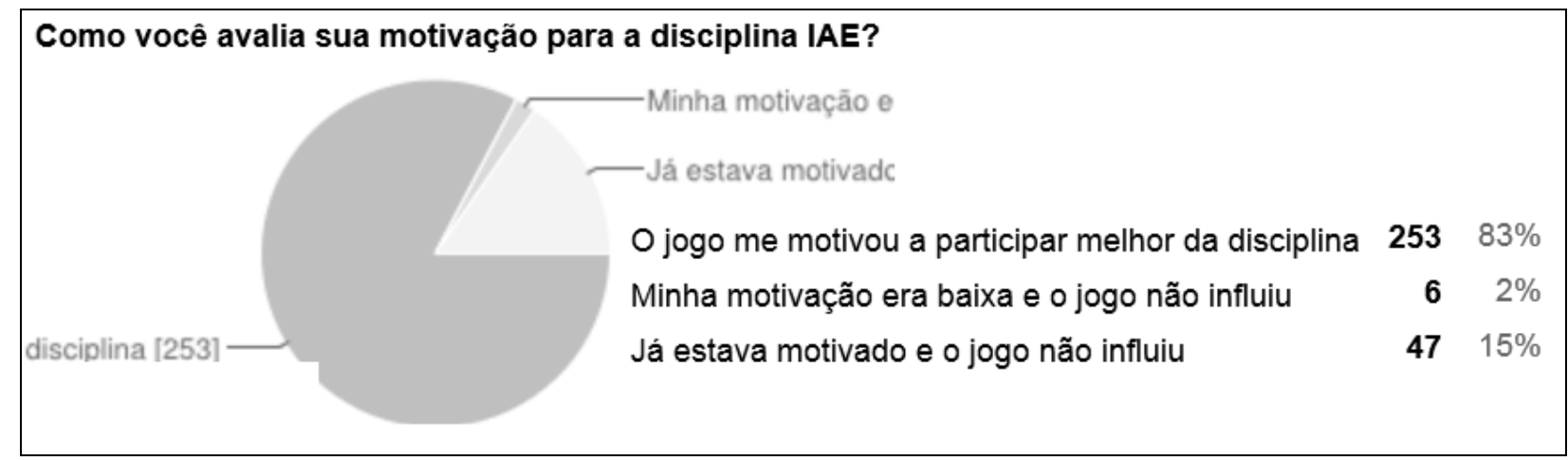

Figura 3: Respostas do questionário de opiniões após a experiência com o ITAE referente à motivação. Total de 306 alunos do curso de IAE. 


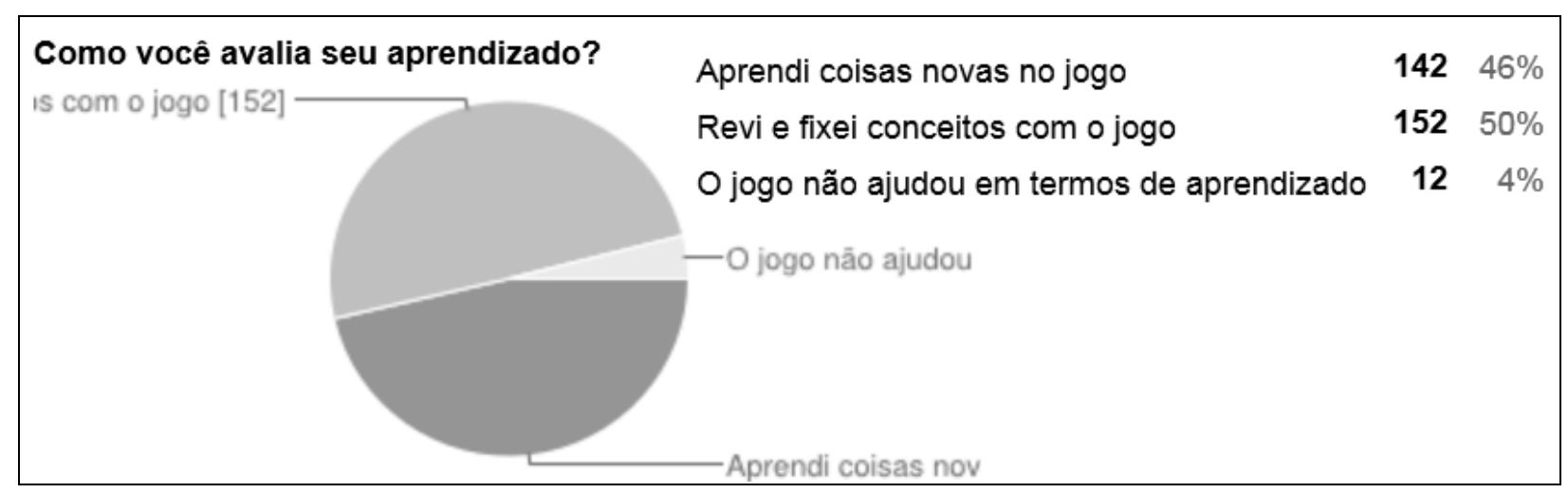

Figura 4: Respostas do questionário de opiniões após a experiência com o ITAE referente à percepção de aprendizagem. Total de 306 alunos do curso de IAE.

\section{Considerações Finais}

Nessa era digital, os chamados objetos digitais de aprendizagem parecem que estão auxiliando os processos educacionais em ambientes escolares presenciais. As tecnologias inovadoras a serem incorporadas ao ensino tradicional são essenciais. O sucesso do seu uso vai depender da forma como venha a ser utilizado pelo professor e, em consequência, pelo aluno. Sabe-se que quando o aluno está motivado e satisfeito, ele provavelmente aprende melhor, armazenando memória de forma duradora e significativa.

Entretanto, neste estudo, o simples fato de disponibilizar um objeto de aprendizagem em ambiente virtual, fora do espaço da sala de aula, parece ter gerado satisfação e boa percepção de aprendizagem. Ainda assim, isso não dá garantia de solução dos problemas de aprendizagem. Quando o aluno percebe que aprende, também se sente mais satisfeito, com maior motivação a estudar e aprender. Mas, o fato de haver satisfação e percepção de aprendizagem não significa que tenha havido real aquisição do conteúdo abordado.

Observou-se pelos resultados apresentados que o ambiente ITAE foi eficiente naquilo que se dispôs a fazer. As opiniões dos alunos mostraram que foi uma experiência agradável, de conteúdo coerente e bem distribuído, que foi capaz de motivar e incentivar aprendizagem. Interessante seria analisar juntamente com esses resultados os dados referentes ao desempenho nas respostas do quiz.

Sugere-se que a metodologia avaliada possa ser utilizada por professores de forma complementar, ressaltando a importância da construção de diálogos que sintonizem metodologias clássicas de ensino, como a aula expositiva, com novas tecnologias, como os ambientes virtuais de jogos de aprendizagem.

A partir do segundo semestre de 2013, o ambiente ITAE será utilizado na disciplina de Exercício Profissional e Deontologia em Fisioterapia, do curso de graduação em Fisioterapia da UnB. Professores e alunos já estão empenhados em adaptar a ferramenta aos conteúdos das disciplinas. 


\section{Referências}

Almeida, S. (1993) "O lugar da afetividade e do desejo na relação ensinar-aprender." Temas em Psicologia, 1(1): 31-44.

Almeida, M. (2003) "Educação à distância na Internet: abordagens e contribuições dos ambientes digitais de aprendizagem." Educação e Pesquisa, 29 (2), 327-340.

Azevedo, A. M. (2008) "Vídeos agregam valor ao trabalho do professor de ciências da saúde". In: XII Ciclo de Palestras sobre Novas Tecnologias na Educação CINTED-UFRGS (2008). Revista Novas Tecnologias na Educação, 6(2): 25-40.

Azevedo, A. M.; Amoretti, M. S. M.; Timm, M. I.; Zaro, M. A. (2004) "Mapas conceituais e o jogo: estratégias pedagógicas de ensino e aprendizagem de bioquímica". Informática na Educação, 7(1): 59-71.

Bushell, D. (1973) "Classroom behavior: a little book for teachers". New Jersey/EUA: Prentice-Hall.

Bruno, A. (2010) "Aprendizagem do adulto educador: plasticidade e redes rizomáticas de formação, via ambiente online". In: Aranha, G.; Sholl-Franco, A. (Orgs.). Caminhos da Neuroeducação. Rio de Janeiro: Ciências \& Cognição.

Bzuneck, J. (2007) "As crenças de auto-eficácia e o seu papel na motivação do aluno." In: Davel, E.; Vergara, S.; Ghardiri, D.P. Administração com arte: experiências vividas de ensino-aprendizagem. São Paulo/SP: Atlas.

Cabral, P.; Timm, M. I.; Thaddeu, R. C.; Leal, M.; Zaro, M. (2005) "Produção e Validação de Aula em Vídeo como Objeto de Ensino para o Curso de Medicina". Revista Novas Tecnologias na Educação, 3(2.

Moraes, M. C.; Torre, S. (2004). "Fundamentos e práticas para reencantar a educação". Petrópolis/RJ: Vozes.

Mota, R. (2010) "Olhando para o futuro: visões da educação brasileira para os próximos dez anos." Revista Tecnologia Educacional, 39 (191), 26-38.

Paula, L. A. L. "Jovens e novas formas de cognição: derrubando estereótipos". In: Aranha, G.; Sholl-Franco, A. (Orgs.). Caminhos da Neuroeducação. Rio de Janeiro: Ciências \& Cognição, 2010.

Pelosi, M. B. (2010) "A tecnologia assistiva como facilitadora do processo de ensino e aprendizagem: uma parceria com o Instituto Helena Antipoff e a Terapia Ocupacional." In: Aranha, G.; Sholl-Franco, A. (Orgs.). Caminhos da Neuroeducação. Rio de Janeiro: Ciências \& Cognição. 
Pereira, A. T. C.; Schmitt, V.; Dias, M. R. (2007) "AVA - Ambientes Virtuais de Aprendizagem." In: Pereira, A. T. AVA - Ambientes virtuais de aprendizagem em diferentes contextos. Rio de Janeiro/RS: Editora Ciência Moderna Ltda.

Soares, S. V. (2010) "Outro Olhar: O audiovisual na arquitetura da aula". Tecnologia Educacional, 39 (190), 7-14.

Timm, M. I.; Schnaid, F.; Zaro, M.; Ferreira-Filho, R. M.; Cabral, P.; Rosa, A. M.; Jesus, M. A. S. (2003) "Tecnologia Educacional: mídias e suas linguagens". Revista Novas Tecnologias na Educação, 1(1).

Timm, M. I.; Zaro, M.; Schnaid, F.; Cabral, P.; Thaddeu, R. C. (2004) "Tecnologia educacional: apoio à representação do professor de Ciência e Tecnologia e instrumento de estudo para o aluno." Revista Novas Tecnologias na Educação, 2(2):2-14.

Timm, M. I.; Bonini-Rocha, A. C.; Schnaid, F.; Zaro, M.; Chiaramonte, M. (2007) "Virada Computacional da Filosofia." Revista Ciências \& Cognição, 10: 2-20.

Timm, M. I.; Ribeiro, L. O. M.; Azevedo, A. M.; Vieira, E. B. (2008) "Game Educacional: Desafios Da Integração De Elementos Ficcionais, Tecnológicos, Cognitivos e de conteúdo." In: SIMPÓSIO BRASILEIRO DE JOGOS PARA COMPUTADOR E ENTRETENIMENTO, PROCEEDINGS OF SBGAMES: GAME \& CULTURE TRACK. Belo Horizonte: UFMG, CD. Buenos Aires, 10-12 nov. p. 107-114.

Timm, M. I.; Ferreira-Filho, R. C. M.; Ribeiro, L. O. M.; Zaro, M.; Schnaid, F. (2009) "As tecnologias educacionais e a discussão sobre ensino de engenharia." In: VI INTERNATIONAL CONFERENCE ON ENGINEERING AND COMPUTER EDUCATION. EDUCATIONG ENGINEERS FOR INNOVATION. Buenos Aires: ICECE, Book of Abstracts. 2009 a.

Timm, M. I.; Thaddeu, R. C.; Bos-Mikich, A.; Cabral, P.; Ferreira-Filho, R. M.; Ribeiro, L. O.; Zaro, M.; Schnaid, F. (2009) "As tecnologias educacionais e a discussão sobre ensino de engenharia." In: VI INTERNATIONAL CONFERENCE ON ENGINEERING AND COMPUTER EDUCATION. EDUCATIONG ENGINEERS FOR INNOVATION, Buenos Aires. Book of Abstracts. Buenos Aires: ICECE, 2009 b.

Zaro, M.; Rosat, R.; Meireles, L. O.; Spindola, M.; Azevedo, A. M.; Bonini-Rocha, A. C.; Timm, M. I. (2010) "Emergência Da Neuroeducação: A Hora E a vez da neurociência para agregar valor à pesquisa educacional." Ciências \& Cognição, 15(1):199-210.

Wojciechowski, T.; Vosgerau, D.S. (2010) A utilização da internet nas escolas municipais de Curitiba. Revista Tecnologia Educacional, 39 (189), 15-34. 